\title{
Iodometric Determination of the Ascorbic Acid (Vitamin C) content of mango and tomato consumed in Mettu Town Ilu Abba Bora Zone, Oromia Ethiopia.
}

\author{
Kebena Gebeyehu Motora ${ }^{1}$ \\ ${ }^{1}$ Mettu University, Faculty of Natural and Computational Sciences, Department of Chemistry, P.O.Box 318 \\ Mettu (Ethiopia)
}

\begin{abstract}
The objective of this study was to determine the ascorbic Acid (Vitamin C) Content of mango and tomato fruit Consumed in Mettu Town of Ethiopia. Representative commercial fruits of mango and tomato were purchased randomly from local market found in Mettu Town which is found in Oromia regional state of Ethiopia and brought to Chemistry Department in Mettu University and preserved in Refrigerator. The fruit samples were first washed with water; thejuice from each fruit was squeezed out, and filtered. Then, the obtained juice was centrifuged until a clear sample was obtained, which was subsequently analyzed for Ascorbic acid content of fresh fruit juices by volumetric method. The results of present study indicated that the concentration of ascorbic acid in each fruits found to be: Mango $(1000.5 \pm 100.5 \mathrm{mg} / 100 \mathrm{~mL})$ and Tomato $(600.75 \pm 50.5 \mathrm{mg} / 100 \mathrm{~mL})$. From the results it can be concluded that the ascorbic acid content of fruits juice (fruit pressing) were found to beMango > Tomato.
\end{abstract}

Key words:Ascorbic acid, friuts, Iodometric determination

\section{Introduction}

Citrus fruits among other uses are sources of food and medicine[1].Ascorbic acid also known as Vitamin C, L-ascorbic acid and the Antiscorbutic Vitamin, when pure is a white crystalline water-soluble vitamin found especially in citrus fruits and vegetables. It is synthesized by most organisms from glucose but man and other primates and various other species must obtain it from their diet [2]. Ascorbic acid is the most abundant vitamin in orange, lemon and grapefruit [3].The citrus species are medium sized tree of the rutacene family. They are evergreen trees that give fruits of different forms and sizes (from round to oblong) which are full of fragrance, flavour and juice. Citrus fruits have a rough, robust and brightcolour (from green to yellow) skin or rind known as epicarp which covers the fruits and protects them from damages [4]. The glands contain the essential oils that the fruit its typical citrus fragrance. The endocarp is rich in soluble sugars and contains significant amounts of ascorbic acid, pectin, fibres, different organic acids and potassium salt which gives the fruit its characteristic citrus flavour [4,5].Ascorbic acid is required in the synthesis of collagen in connective tissues, neurotransmitters, steroid hormones, carnitine, and conversion of cholesterol to bile acid and enhances iron bio-availability [6].

Ascorbic acid is a great antioxidant and helps to protect the body against pollutants [7,8]. It is also a biological reducing agent linked to prevention of degenerative disease such as cataracts, certain cancers and cardiovascular diseases [9]. It promotes healthy cell development, proper calcium absorption, normal tissue growth and repair such as healing of wounds and burns and strengthening the wall of the capillaries. Ascorbic acid is needed for healthy gums, to help protect against infection and assisting with clearing up infection; and is thought to enhance the immune system and help reduce cholesterol levels and high blood pressure [10].A deficiency of ascorbic acid in the body results in scurvy, a disease characterized by sore, spongy gums, loose teeth, fragile blood vessels, swollen joints and anaemia [11].The consumption of fruit juices and vegetables are beneficial and the health effects of fruits are ascribed, in part to ascorbic acid, a natural antioxidant which may inhibit the development of major clinical conditions including cardiovascular diseases and cancer[12-14].

Numerous analytical techniques are available for the determination of vitamin $\mathrm{C}$ in different matrices. Some of the techniques include: direct titration[15-18] fluorometric methods, chromatographic methods, and Electrochemical [6,18-22]. However, some of these methods are time-consuming, some are costly, some need special training operators, or they suffer from the insufficient sensitivity or selectivity[6]. In this research titration method was used because it is accurate and precise method to determine vitamin $\mathrm{C}$ compared other methods as high pressure liquid chromatography (HPLC) method and enzymatic methods[9].

Ascorbic acid which is an effective reducing agent belongs to endiol group and has two alcoholic groups with acidic character. It can be quantitatively and reversibly oxidized by different oxidizing agent in 
aqueous solutions[18]. It is a labile substance, as it is easily degraded by enzymes and atmosphericoxygen. Its oxidation can be accelerated by excessive heat, light,and heavy metal cations[6,22]. To my knowledge so far there is no coordinated investigation of the levels of Ascorbic acid in various types of fruits items including mango and tomato Commercially available in Market of Mettu Town. The aim of the present study was to determine the amount ascorbic acid found in Mango and tomato fruits of Mettu town of Ilu Abba bora zone, Oromia, south west Ethiopia.

\section{Material And Methods}

Chemicals and Apparatus: All the chemicals used for the experimental purposes were of analytical grade and used without further purification. The chemicals used for this experimental purpose include: Distilled water, $1 \mathrm{M}$ potassium

iodide $\mathrm{KI}(\mathrm{Scharlau}), \quad 0.5 \mathrm{M}$ Sulphuric acid $\left(\mathrm{H}_{2} \mathrm{SO}_{4}\right)$, Sodium Thiosulphate $\left(\mathrm{Na}_{2} \mathrm{~S}_{2} \mathrm{O}_{3}\right)$, Iodine (NICE, India) and fresh starchindicator or solution. Beam balance, titration apparatus, beaker, volumetric flask, measuring cylinder and test tube.

Experimental Procedure: Sampling:The commercial fruits such of mango and tomato were purchased from local market found in Mettu town, Ilu Abba bora zone Oromia Regional state of Ethiopia and brought to chemistry department ofMettu University and preserved in Refrigerator.

Sample Preparation:Various fruits ofmango and tomato were bought from fruit markets available in Mettu town and freshly prepared fruit juices were obtained by fruit pressing. The fruit samples were first washed with water, the juice from each fruit was squeezed out, and filtered. Then, the obtained juice was centrifuged until a clear sample was obtained, which was subsequently analyzed[8].

Determination of Vitamin C Content of the Fresh Fruit Juice:Using standardized sodium thiosulphate solution, vitamin $\mathrm{C}$ content of the fresh fruit juice was determined. The methods adopted were from[23].

\section{Results And Discussion}

The concentration of ascorbic acid in two fruits consumed in Mettu town in Ethiopia were calculated and found to be different in each fruits;Mango $(1000.5 \pm 100.5 \mathrm{mg} / 100 \mathrm{~mL})$ and Tomato $(600.75 \pm$ $50.5 \mathrm{mg} / 100 \mathrm{~mL}$ ).Ascorbic acid content was high in mango and low in tomato fruits were found.

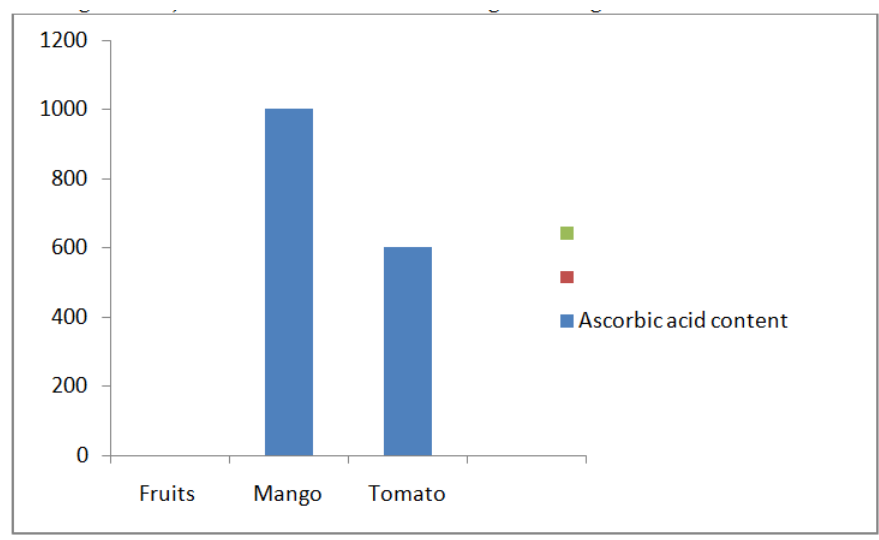

Figure 1 Amount of Ascorbic acid in $100 \mathrm{ml}$

In present study the ascorbic content of mango juice (fruit pressing) was found to be $1000.5 \pm 100.5 \mathrm{mg} / 100 \mathrm{~mL}$. The amount ascorbic acid found in mango fruit of Jimma town was $1104.459 \pm 204.595 \mathrm{mg} / 100 \mathrm{ml}[24]$

It was reported that the ascorbic acid contents of freshly prepared mango juice were obtained to be $14.65 \pm 0.151 \mathrm{mg} / 100 \mathrm{~mL}$. Md kanafe and shamsul Azri (2009) reported that the ascorbic acid contents of freshly prepared mango juice was about $28 \mathrm{~g} / 100 \mathrm{~mL}$ for nature fruit[25]. Gunjan Kashyap and Mangla Dave Gautamreported that the ascorbic acid content of freshly prepared Mango fruits $26 \mathrm{~g} / 100 \mathrm{~mL}$ for nature fruit pulp[15].The finding of this study is in agreement with that research done in Jimma town for determination of Ascorbic acid and there is also significant difference among results obtained by others researchers. The observed differences in the contents of vitamin $\mathrm{C}$ studied in the same method may be as a result of differences in maturity stage and regional varieties of fruits. The amount of vitamin $\mathrm{C}$ could even vary between different samples of the same species. Different techniques of measuring and squeezing process may also affect thevitamin $\mathrm{C}$ content of fruit juices. Factors including climate, temperature and amount of nitrogen fertilizers used in growing the plant and climatic conditions such as light can affect the concentration of AA in fruits. For instance, increasing the amount of nitrogen fertilizer from 80 to $120 \mathrm{kgha}-1$ decreased the 
vitamin $\mathrm{C}$ content by $7 \%$ in cauliflower.The amount of vitamin $\mathrm{C}$ content in fruit juices can also be affected by the type of storage. Fruit juices must be stored at cool temperature. When the fruit juices are stored at cool temperature, the vitamin $\mathrm{C}$ content does not loss, however, storing fruit juices at higher temperatureresult in loss of vitamin $\mathrm{C}$ content. This is because vitamin $\mathrm{C}$ is more sensitive to temperature and it can easily oxidize[6].

\section{Conclusion}

From the results it can be concluded that the ascorbic acid content of fruits juice mango > tomato were determined by Iodometeric titration.Vitamin $\mathrm{C}$ or ascorbic acid is important for the human body. Inadequate intake will result in the symptomsof scurvygingival bleeding, and so on; excess AA intake willalso lead to urinary stone, diarrhea and stomach convulsion. That is why ascorbic acid content of foodstuffs and beverages represents a relevant indicator of quality which has to be carefully monitored, regarding its variation during manufacturing and storage.

\section{Acknowledgement}

I gratefully acknowledgeDepartment of Chemistry, Mettu University for its unreserved help and encouraging me by providing necessary materials.

\section{References}

[1]. K.J. Thurlor. and I.D. Lumley. (1989). Fruit classification. International Journal of Plant Sciences. 13(5) 85-91.

[2]. J.E. Alibone. (2000). Livestock feeds and feeding. Nutrition Abstracts and Reviews. 72(12) 651-659.

[3]. A. Ralph. and D.A. Bender. (2000). Vitamin C, Journal of Human Nutrition and Dietetics. 2(2) 75-81.

[4]. D.E. Okwu and I.N. Emenike. (2007). Nutritive value and mineral content of different varieties of citrus fruits. Journal of Food Technology. 5(2) 105-108.

[5]. G.D.P. Roger. (2002). Encyclopedia of medicinal plants, education and healthy library. Editorial Safeliz S.L. Spalm. 1,153$154 ; 265-267$.

[6]. K.M. Robert. , K.G. Daryl. , A.M. Peter. and W.R. Victor. (2000). Structure and functions of watersoluble vitamins, Harper's Biochemistry.25 ed., McGraw-Hill New York, pp. 640-641.

[7]. D.E. Okwu. (2004). Phytochemicals and vitamin content of indigenous spices of South Eastern Nigeria. Journal of Sustainable Agriculture and Environment. 6: 30-34.

[8]. D.E. Okwu. (2005). Phytochemicals, vitamins and mineral contents of two Nigerian medicinal plants. International Journal of Molecular Medicine and Advance Sciences. 1(4) 375-381.

[9]. N. Gary. (2004). The antioxidant vitamin-vitamin C. Journal of Raw Materials and Research. 1(1) 16-20.

[10]. R.H. Larsen. (1997). Vitamin C: Your ultimate health insurance. International Journal of Alternative and Complementary Medicine. 15(8)19-26

[11]. N. Piff. , K. Law., B. Mauro and J. Norris. (1998). Vitamins and minerals. American Journal of Family Health. 1(1) 32-35.

[12]. Sarkar N., Srivastava P.K. and Dubey V.K. (2009). Curr Nutri Food Sci.(5):53-55.

[13]. Lee S.K. and Kader A. A. (2000). Postharvest Biology Technology, 20(3):207-220.

[14]. Gardner P.T., White T. A. C., McPhail D. B. and Duthie G.G. (2000). Food Chem., 68, 471-474

[15]. Gunjan K. and Mangla D.G., Analysis of Vitamin C in Commercial and Naturals substances by Iodometric Titration found in Nimar and Malwa regeion, J Sci Res Phar, 1(2), 8 (2012)

[16]. Papuc C., Pop A. and Serban M., Metode Analitice in Biochimia Veterinara, Editura Printech, Bucharest, Romania, 167$169(2001)$

[17]. Balan D., Pele M., Artimon M. and Luta G., Bioactive compounds in sea buckthorn fruits and in some products obtained by their processing, Rev. Cytol. Biol. Veg. Bot., 28, 364-368 (2005)

[18]. Matei N., Magearu V., Birghila S. and Dobrinas S., The determination of vitamin C from sweet cherries and cherries. Revista De Chimie (Bucharest), 55, 294-296 (2004)

[19]. Iwase H., Use of nucleic acids in the mobile phase for the determination of ascorbic acid in foods by highperformance liquid chromatography with electrochemical detection, J Chromatogr A, 881, 327-330 (2000)

[20]. Borowski J., Szajdek A., Borowska E.J., Ciska E. and Zielinski H., Content of selected bioactive components and antioxidant properties of broccoli (Brassica oleracea L.), Eur Food Res Technol, 226, 459-465 (2008)

[21]. Arya S.P., Mahajan M. and Jain P., Nonspectrophotometric methods for the determination ofvitamin C, Anal Chim Acta, 417, 1-14 (2000)

[22]. Vermeir S., Hertog M.L.A.T.M., Schenk A., BeullensK., Nicolai B.M. and Lammertyn J., Evaluation and optimization of high-throughput enzymatic assays for fast 1-ascorbic acid quantification in fruit and vegetables, Anal Chim Acta, 618, 94-101 (2008)

[23]. Analysis of commercial vitamin C tablets http://www.123 Help Me. com. of view aspid =15015 (2014)

[24]. Dereje Alemu Bekele and Girma Selale Geleta Iodometric Determination of the Ascorbic Acid (Vitamin C) content of some Fruits consumed in Jimma Town Community in Ethiopia Res. J. Chem. Sci. Vol. 5(1), 60-63, January (2015).

[25]. Kanafe Md and Shamsul A., Analysis of vitamin C incommercial fruit juices by Iodometric Titration / Shamsul Azrin Md. Kanafe. Bachelor Degree thesis, Universiti Teknologi MARA, 1-24 (2009), 